\title{
Kinetic study of the thermal decomposition of cellulose nanocrystals with different polymorphs, cellulose I and II, extracted from different sources and using different types of acids
}

\author{
Mariana Alves Henrique ${ }^{a}$, Wilson Pires Flauzino Neto ${ }^{a}$, Hudson Alves Silvério ${ }^{a}$, \\ Douglas Ferreira Martins ${ }^{\mathrm{a}}$, Leandro Vinícius Alves Gurgel ${ }^{\mathrm{b}}$, Hernane da Silva Barud ${ }^{\mathrm{c}}$, \\ Luís Carlos de Morais ${ }^{\mathrm{d}}$, Daniel Pasquini ${ }^{\mathrm{a}, *}$ \\ a Instituto de Química, Universidade Federal de Uberlândia, Campus Santa Mônica, Av. João Naves de Ávila, 2121, 38400-902 Uberlândia, Minas Gerais, \\ Brazil \\ ${ }^{\mathrm{b}}$ Departamento de Química, Instituto de Ciências Exatas e Biológicas, Universidade Federal de Ouro Preto, Campus Universitário Morro do Cruzeiro, \\ 35450-000 Ouro Preto, Minas Gerais, Brazil \\ ' Instituto de Química de Araraquara, Universidade Estadual Paulista Júlio de Mesquita, Campus de Araraquara, Rua Professor Francisco Degni, 55, \\ 14800-900 Araraquara, São Paulo, Brazil \\ d Instituto de Ciências Exatas, Naturais e Educação, Universidade Federal do Triângulo Mineiro, Av. Dr. Randolfo Borges, 1400, Univerdecidade, 38064-200 \\ Uberaba, Minas Gerais, Brazil
}

\section{A R T I C L E I N F O}

\section{Article history:}

Received 2 February 2015

Received in revised form 5 June 2015

Accepted 20 June 2015

Available online 3 July 2015

\section{Keywords:}

Cellulose nanocrystals

Thermal decomposition

Decomposition kinetics

Kissinger

Flynn-Wall-Ozawa

\begin{abstract}
A B S T R A C T
Cellulose nanocrystals (CNs) were extracted from different sources by acid hydrolysis using $\mathrm{H}_{2} \mathrm{SO}_{4}$ and $\mathrm{HCl}$. The thermal decomposition of resulting $\mathrm{CNs}$ was studied by thermogravimetric analysis (TGA). The kinetic parameters were determined using the Flynn-Wall-Ozawa (FWO) and Kissinger methods. CNs were also characterized by X-ray diffraction (XRD), Atomic Force Microscopy (AFM), elemental analysis (EA), Zeta Potential (ZP) and degree of polymerization (DP). The results of the XRD analysis showed different profiles, making it possible to differentiate cellulose I from cellulose II. The results obtained by the FWO method showed that cellulose II CNs had an increased activation energy $\left(E_{\mathrm{a}}\right)$ with conversion $(\alpha)$, while in CNs of cellulose I the $E_{\mathrm{a}}$ remained constant or decreased slightly. This difference between $E_{\mathrm{a}}$ values for the thermal decomposition of $\mathrm{CNs}$ was mainly attributed to different crystalline arrangements of cellulose I and cellulose II, and to the type of acid employed.
\end{abstract}

(C) 2015 Elsevier B.V. All rights reserved.

\section{Introduction}

There is a growing interest in developing novel polymer materials derived from renewable resources such as cellulose. In this context, recent studies have shown that cellulose nanocrystals (CNs) could be used to prepare a wide range of composite materials with improved properties (Eichhorn et al., 2010; Siqueira et al., 2010). As a direct result, they have attracted immense interest as a novel nanostructured material during recent years. CNs are nanoparticles of high crystallinity derived from cellulosic fibres. $\mathrm{CNs}$ are very high-value materials, since they can change the performance of existing products as well as function as a raw material used to create new, unique and improved products. Their unique

\footnotetext{
* Corresponding author. Fax: +55 3432394208.

E-mail addresses: pasquini@iqufu.ufu.br, danielpasquini2005@yahoo.com.br (D. Pasquini).
}

combination of amazing physicochemical properties and environmental benefits allow CNs to offer a wide range of potential applications.

At the present moment, the main application of $\mathrm{CNs}$ is as a reinforcing agent in the nanocomposite research field. Other research fields with potential applications are packaging, paints, coatings, special papers, cosmetics, pharmaceuticals, biomedical materials, textiles, the automotive industry, aerospace, building materials, and the electronics and electrical industry, among others. In addition, CNs come from renewable natural sources that are very plentiful and inexpensive, and it is not necessary to synthesize them. Their nanometric dimensions allow the production of composite films with excellent visible light transmittance, and CNs can be easily chemically modified since their molecular structure has reactive side surface hydroxyl groups which facilitate the grafting of chemical moieties in order to achieve different surface properties (Samir et al., 2005; Li et al., 2009; Liu et al., 2010; Lahiji et al., 2010; Moon et al., 2011; Peng et al., 2011; Flauzino Neto et al., 2013). 
Currently, CNs are obtained by different methods, including enzymatic hydrolysis, acid hydrolysis and hydrolysis assisted by ultrasound, among others (Filson et al., 2009; Filson and DawsonAndoh, 2009). However, the most used method is acid hydrolysis. During the reaction, the more accessible amorphous regions are rapidly attacked in comparison with the crystalline regions that remain intact after the process (Habibi et al., 2010). With regard to extraction by acid hydrolysis, the temperature, reaction time, type of acid, concentration of acid and the acid-to-solid ratio are all important parameters since they affect the morphology and physicochemical properties of CNs (Silva and D'Almeida, 2009; Habibi et al., 2010; Peng et al., 2011; Teixeira et al., 2011). The aspect ratio $(L / D)$ of the CNs is a crucial parameter that has a significant influence on the ability of the nanoparticles to enhance the properties of a polymer matrix when they are incorporated into it. Therefore, the conditions for acid hydrolysis must be carefully considered and controlled in order to obtain a material with the desired morphology and properties (Roman and Winter, 2004; Martínez-Sanz et al., 2011).

Since thermoplastic processing temperatures often exceed $200^{\circ} \mathrm{C}$, the thermal stability of these nanocrystals is a key factor determining their use as effective reinforcement materials (Roman and Winter, 2004). Jeong et al. (2010) obtained CNs from microcrystalline cellulose (MCC) by acid hydrolysis using sulphuric and hydrochloric acids as catalysts. They also studied the thermal decomposition behavior of CNs and the activation energy $\left(E_{\mathrm{a}}\right)$ was evaluated by Broido's method. Roman and Winter (2004) produced CNs from bacterial cellulose by acid hydrolysis using sulfuric acid as a catalyst under different hydrolysis conditions. They also determined the thermal decomposition behavior of CNs and $E_{\mathrm{a}}$ was also evaluated by Broido's method. The problem involved with determining $E_{\mathrm{a}}$ using the Broido's method is that the calculation is made using a single thermogravimetric (TG) curve at a specific heating rate, which makes it susceptible to errors from reproducibility of the TG curve. Therefore, a more precise method as Flynn-Wall-Ozawa (FWO) generally produces better and more reliable results because it uses various TG curves obtained at different heating rates to determine $E_{\mathrm{a}}$.

The aim of this study was to extract cellulose nanocrystals from different sources using two types of acid $\left(\mathrm{H}_{2} \mathrm{SO}_{4}\right.$ and $\left.\mathrm{HCl}\right)$ in order to obtain $\mathrm{CNs}$ with different morphologies and properties. Then, a study of the thermal decomposition of these different CNs was carried out to assess their thermal decomposition properties. The Flynn-Wall-Ozawa (FWO) and Kissinger methods were employed to determine the activation energy and pre-exponential factor for thermal decomposition of the extracted CNs. These studies will provide enough data to evaluate critically the possibility of applying $\mathrm{CNs}$ into polymer matrices in the preparation of nanocomposites, for example. Furthermore, this study will also demonstrate which CNs are most suitable for application in polymer processing requiring high melting temperatures without degradation of the CNs.

\section{Experimental}

\subsection{Materials}

The raw materials used in this study were the cellulose from purified mango seeds (PMS), bleached Kraft pulp (KP) from Eucalyptus urograndis, and cellophane (CELL) obtained by the industrial process. The mango seeds were supplied by Ebba. (Araguari, Minas Gerais, Brazil). The species used was Ubá mango (Mangifera indica L.). The eucalyptus Kraft pulp sheets were supplied by the Suzano company (Limeira, São Paulo, Brazil) and the cellophane sheets were supplied by the Coopercel company (São Paulo, Brazil). Sulphuric acid (98.0wt.\%), hydrochloric acid (37 wt.\%), sodium hydroxide, and potassium hydroxide were purchased from Vetec (Brazil). Sodium chlorite $\left(\mathrm{NaClO}_{2}\right.$, technical grade, $\left.80 \%\right)$ and cellulose membrane (cat. no. D9402) were purchased from Sigma-Aldrich. Glacial acetic acid was purchased from Synth (Brazil) and cupric ethylenediamine was purchased from Cromoline (Brazil).

\subsection{Extraction of cellulose nanocrystals (CNs)}

\subsubsection{CNs from mango seeds (MS)}

Initially, the mango seeds (MS) were ground in a mill and subsequently sifted to pass through an 18-mesh sieve. Then, the MS were treated four times with a $2 \%(\mathrm{w} / \mathrm{w})$ aqueous sodium hydroxide solution for $4 \mathrm{~h}$ at $100^{\circ} \mathrm{C}$ under mechanical stirring. The alkali-treated MS were filtered off and washed with an excess of distilled water until the alkali was completely removed ( $\mathrm{pH} 7)$. The alkali-treated MS were then dried at $40^{\circ} \mathrm{C}$ for $24 \mathrm{~h}$ in an oven with forced air circulation. After this treatment, the fibres were bleached with a solution made up of equal parts (1:1/v:v) of a solution composed of acetate buffer $(27 \mathrm{~g}$ of $\mathrm{NaOH}$ and $75 \mathrm{~mL}$ of glacial acetic acid, diluted to $1 \mathrm{~L}$ in distilled water) and aqueous sodium chlorite (1.7 wt.\% $\mathrm{NaClO}_{2}$ in water). The bleaching treatment was performed twice at $80^{\circ} \mathrm{C}$ for $6 \mathrm{~h}$. The bleached fibres were filtered off and washed with an excess of distilled water until the wash water was $\mathrm{pH} 7$, and subsequently dried at $40^{\circ} \mathrm{C}$ for $24 \mathrm{~h}$ in an oven with forced air circulation (de Rodriguez et al., 2006). The fibre content throughout these chemical treatments was about $4-6 \%(w / w)$. The resulting material obtained after these treatments was referred to as purified mango seeds (PMS).

After the preparation and purification treatments, the PMS was submitted to a nanocrystal extraction procedure through acid hydrolysis. The extraction of CNs from PMS was performed using two types of acids, $\mathrm{H}_{2} \mathrm{SO}_{4}$ and $\mathrm{HCl}$, respectively. The extraction of CNs from PMS with sulphuric acid was performed at $40^{\circ} \mathrm{C}$ for 10 min using a solid-to-liquid ratio of 1:20 (w:v) with $11.12 \mathrm{~mol} \mathrm{~L}^{-1}$ $\mathrm{H}_{2} \mathrm{SO}_{4}$ solution under vigorous and constant magnetic stirring. The extraction of CNs from PMS using hydrochloric acid was carried out at $40^{\circ} \mathrm{C}$ for $225 \mathrm{~min}$ using a solid-to-liquid ratio of $1: 20$ (w:v) with $11.97 \mathrm{~mol} \mathrm{~L}^{-1} \mathrm{HCl}$ solution. Immediately at the end of acid hydrolysis, the suspension of CNs was diluted ten-fold with cold distilled water to stop the hydrolysis reaction and centrifuged for $10 \mathrm{~min}$ at $7500 \mathrm{rpm}$ on a refrigerated centrifuge (Model 5804R from the Eppendorf company) to remove excess acid. The CNs from PMS were then dialyzed against water using a cellulose membrane to remove acid residues, inorganics and soluble sugars until $\mathrm{pH} 7$ was reached ( $\sim 4$ days). Subsequently, the suspension of $C N s$ from the dialysis process was sonicated for $10 \mathrm{~min}$ and stored in a refrigerator at $4{ }^{\circ} \mathrm{C}$ prior to the analyses. Some drops of chloroform were added to the $\mathrm{CN}$ suspension as an inhibitor to avert the growth of microorganisms.

\subsubsection{CNs from Kraft pulp (KP)}

The extraction of CNs from Kraft pulp (KP) with $\mathrm{H}_{2} \mathrm{SO}_{4}$ was performed at $45^{\circ} \mathrm{C}$ for $50 \mathrm{~min}$ using a solid-to-liquid ratio of $1: 20$ (w:v) with $9.17 \mathrm{~mol} \mathrm{~L}^{-1} \mathrm{H}_{2} \mathrm{SO}_{4}$ solution. The extraction of CNs from KP with $\mathrm{HCl}$ was carried out at $45^{\circ} \mathrm{C}$ for $75 \mathrm{~min}$ using a solid-to-liquid ratio of $1: 25(\mathrm{w}: \mathrm{v})$ with $11.97 \mathrm{~mol} \mathrm{~L}^{-1} \mathrm{HCl}$ solution. At the end of the hydrolysis the reaction was stopped and the suspension of CNs extracted using $\mathrm{H}_{2} \mathrm{SO}_{4}$ or $\mathrm{HCl}$ was purified using the procedure described in Section 2.2.1.

\subsubsection{CNs from cellophane (CELL)}

The extraction of CNs from cellophane (CELL) with $\mathrm{H}_{2} \mathrm{SO}_{4}$ was performed at $45^{\circ} \mathrm{C}$ for $10 \mathrm{~min}$ using a solid-to-liquid ratio of $1: 25$ (w:v) with $11.12 \mathrm{~mol} \mathrm{~L}^{-1} \mathrm{H}_{2} \mathrm{SO}_{4}$ solution. The extraction of CNs from CELL with $\mathrm{HCl}$ was carried out at $45^{\circ} \mathrm{C}$ for 30 min using a solid- 
to-liquid ratio of $1: 25(\mathrm{w}: \mathrm{v})$ with $11.97 \mathrm{~mol} \mathrm{~L}^{-1} \mathrm{HCl}$ solution. At the end of the hydrolysis, the reaction was stopped and the suspension of $\mathrm{CNs}$ extracted using $\mathrm{H}_{2} \mathrm{SO}_{4}$ or $\mathrm{HCl}$ was purified using the procedure described in Section 2.2.1.

\subsection{Elemental analysis}

Elemental analysis was performed on a CHNS-EA1110/O CE Instruments elemental analyser in order to estimate the sulphur content (SC) in the different CNs prepared after hydrolysis using $\mathrm{H}_{2} \mathrm{SO}_{4}$ or $\mathrm{HCl}$.

\subsection{Zeta-potential (ZP)}

Potential charges on the surface of the different CNs were measured on a Malverne 3000 Zetasizer NanoZS (Malverne Instruments, UK). The CNs suspensions ( $0.05 \mathrm{wt} . \%)$, previously sonicated for $5 \mathrm{~min}$, were prepared in deionized water and analyzed to determine the zeta-potential of the CNs suspensions.

\subsection{Degree of polymerization (DP)}

The degree of polymerization (DP) of each CNs preparation was calculated according to TAPPI T 230 OS-76 and SCAN - C 15:62 standards. The degree of polymerization (DP) was calculated from the value of intrinsic viscosity $[\eta]$ using the relationship (Eq. (1)) proposed by Inmergut, Shurtz and Mark (SCAN-C15: 62, 1962).

$\mathrm{DP}^{0.905}=0.75[\eta]$

where the values of 0.905 and 0.75 are constants characteristic of the polymer-solvent system and $[\eta]$ is the intrinsic viscosity $\left(\mathrm{mLg}^{-1}\right)$.

The intrinsic viscosities [ $\eta$ ] of the CNs were obtained by measuring the flow of solvent and solutions in an Ostwald viscometer. The solvent used was a mixture of a solution of bis(ethylenediamine) copper(II) hydroxide and water. The intrinsic viscosities $[\eta]$ were determined from Eq. (2).

$[\eta]=\frac{\sqrt{\left[2 n_{\mathrm{sp}}-\ln \left(n_{\mathrm{rel}}\right)\right]}}{C}$

where $n_{\text {rel }}$ is the relative viscosity given by the ratio of the flow time of the solution of CNs and the flow time of the solvent, $n_{\mathrm{sp}}$ is the specific viscosity given by $\left(n_{\text {rel }}-1\right)$, and $C$ is the concentration of the solution of CNs in $\mathrm{g} \mathrm{mL}^{-1}$.

\section{6. $X$-ray diffraction $(X R D)$}

The X-ray diffractograms of the different CNs prepared were obtained on a Shimadzu LabX XRD-6000 diffractometer operating at a voltage of $40 \mathrm{kV}$ with a current of $30 \mathrm{~mA}$ and $\mathrm{Cu} \mathrm{K \alpha}$ radiation $\left(1.5406 \AA\right.$ ) at $25^{\circ} \mathrm{C}$ with $2 \theta$ from 5 to $40^{\circ}$ and a scan rate of $1^{\circ} \mathrm{min}^{-1}$. All samples of $\mathrm{CNs}$ were dried at $50^{\circ} \mathrm{C}$ for $12 \mathrm{~h}$ in an oven with forced air circulation prior to analysis. The crystallinity index ( $\mathrm{CrI})$ of the CNs was determined by the Segal method (Segal et al., 1959) (cellulose I) or the Revol method (Revol et al., 1987) (cellulose II), as shown in Eqs. (3) and (4), respectively.

$\mathrm{CrI}=\left(\frac{I_{200}-I_{\mathrm{am}}}{I_{200}}\right) \times 100$

$\mathrm{CrI}=\left(\frac{I_{110}-I_{15}}{I_{110}}\right) \times 100$

where $I_{200}$ and $I_{110}$ are the maximum intensities (in arbitrary units) of the 200 and 110 lattice diffractions, respectively, and $I_{\mathrm{am}}$ and $I_{15}$ are the intensities of diffractions in the same units at $2 \theta=18^{\circ}$ and $15^{\circ}$, respectively. $I_{200}$ and $I_{110}$ represent both crystalline and amorphous regions, while $I_{\mathrm{am}}$ and $I_{15}$ represent only the amorphous portion. The Miller indexes employed in these equations are in agreement with French (2014).

\subsection{Atomic force microscopy (AFM)}

AFM measurements were performed on a Shimadzu SPM-9600 to evaluate the morphology of the different CNs prepared. A drop of a diluted aqueous CNs suspension (about $5 \times 10^{-5} \mathrm{~g} \mathrm{~mL}^{-1}$ ) was put on a freshly cleaved mica surface and air-dried. AFM images were obtained at $25^{\circ} \mathrm{C}$ in a dynamic mode with a scan rate of $1 \mathrm{~Hz}$ using Si tips with a curvature radius of less than $10 \mathrm{~nm}$ and a spring constant of $42 \mathrm{~N} \mathrm{~m}^{-1}$. The dimensions of the CNs were determined using VectorScan software (software for Shimadzu's SPM-9600). To eliminate the effect of tip radius on width measurements, the heights of the CNs measured, which were not subject to peak broadening artefacts, were assumed to be cylindrical in shape (Beck-Candanedo et al., 2005). About a hundred CNs were randomly selected to determine the average length, width and aspect ratio. For each individual cellulose nanocrystal, one measurement of length and two measurements of diameter were performed to calculate the aspect ratio.

\subsection{Thermogravimetric analysis (TGA)}

Samples of CNs ranging from 5 to $7 \mathrm{mg}$ previously dried in a forced air oven at $50^{\circ} \mathrm{C}$ for $4 \mathrm{~h}$ were weighed on an aluminium pan. The thermogravimetric analysis was carried out on a Shimadzu DTG-60H Differential Thermal Gravimetric Analyser under nitrogen atmosphere at a flow rate of $30 \mathrm{~mL} \mathrm{~min}^{-1}$ from 25 to $600^{\circ} \mathrm{C}$. The analysis was carried out at four different heating rates $(5,10$, 20 and $40^{\circ} \mathrm{C} \mathrm{min}^{-1}$ ). The results obtained were used to calculate the kinetics parameters for thermal decomposition of the different CNs prepared.

\subsubsection{Theoretical approach}

The rate of a reaction of thermal decomposition of a solid can be described by Eq. (5).

$\frac{d \alpha}{d t}=k(T) f(\alpha)$

where $t$ is reaction time, $k(T)$ is a constant depending on the temperature $(T)$, and $f(\alpha)$ is a function describing how the rate constant of a reaction changes with the extent of reaction or conversion $(\alpha)$. Conversion $\alpha$ at a time $t$ is defined by Eq. (6).

$\alpha=\frac{w_{0}-w_{t}}{w_{0}-w_{\mathrm{f}}}$

where $w_{0}$ and $w_{\mathrm{f}}$ are the initial sample weight and final sample weight $(\mathrm{mg})$, and $w_{t}(\mathrm{mg})$ is the weight at a time $t$.

The dependence of the reaction rate constant with temperature can generally be described by the Arrhenius equation. Thus, the reaction rate for the decomposition of a solid can be described as Eq. (7).

$\frac{d \alpha}{d t}=A e^{\left(\frac{E a}{R T}\right)} f(\alpha)$

where $A$ is the pre-exponential factor, $E_{\mathrm{a}}$ is the activation energy of Arrhenius, and $R$ is the ideal gas constant.

The rate expression described by Eq. (7) can be converted into a non-isothermal rate expression, Eq. (8), relating the reaction rate as a function of temperature at a constant heating rate $\beta$ (RamajoEscalera et al., 2006; Flynn, 1983).

$\frac{d \alpha}{d T}=\frac{A}{\beta} e^{\left(\frac{E_{a}}{R T}\right) f(\alpha)}$

where $\beta$ is the heating rate. 

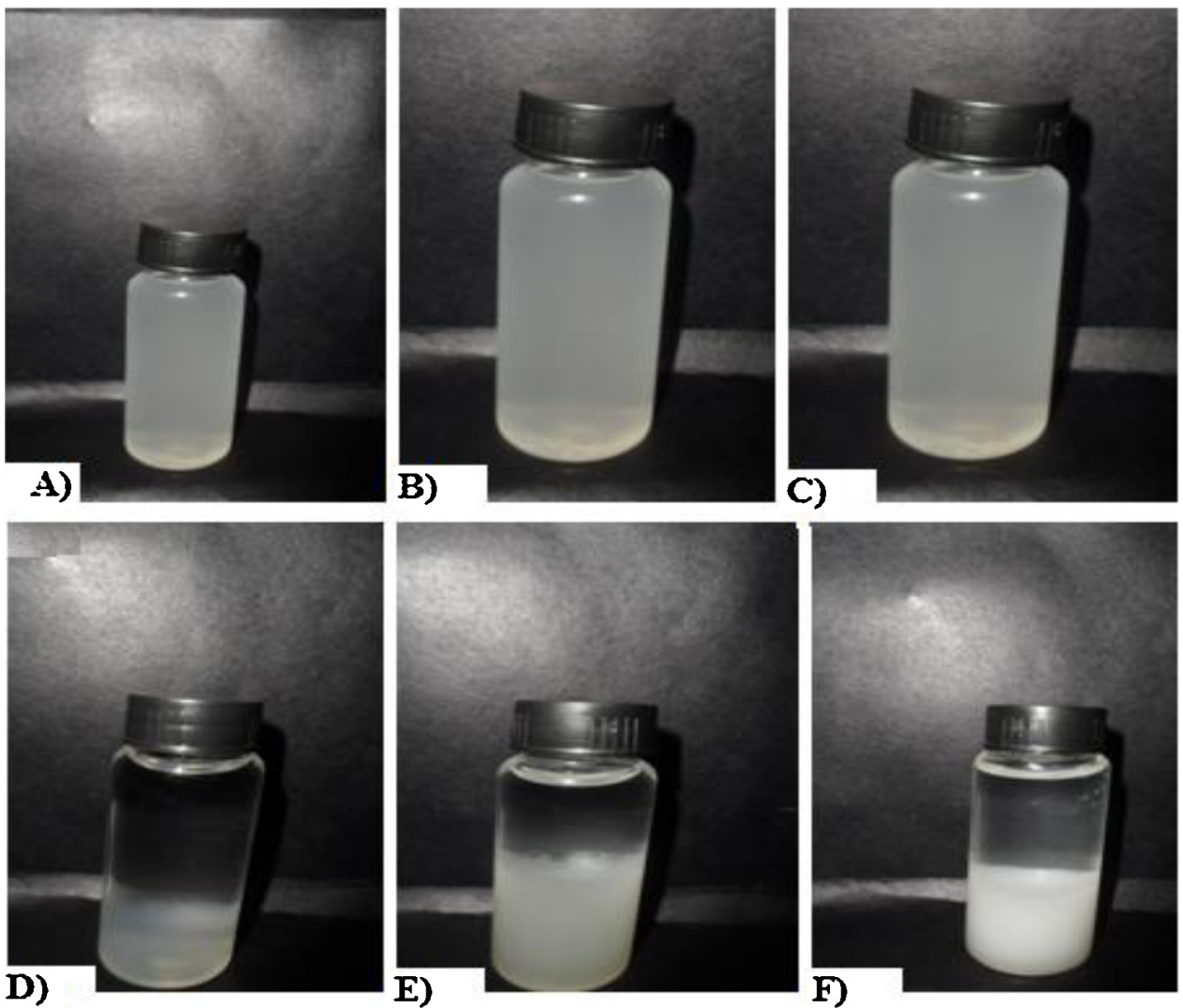

Fig. 1. CNs suspensions; (A) Cellophane $-\mathrm{H}_{2} \mathrm{SO}_{4}$; (B) Mango seed $-\mathrm{H}_{2} \mathrm{SO}_{4}$; (C) Kraft pulp - $\mathrm{H}_{2} \mathrm{SO}_{4}$; (D) Cellophane - $\mathrm{HCl}$; (E) Mango seed - $\mathrm{HCl}$; (F) $\mathrm{Kraft}$ pulp - $\mathrm{HCl}$.

Integrating Eq. (8) by separation of variables gives Eq. (9) as follows (Balogun et al., 2014; Flynn, 1983).

$\int_{0}^{x} \frac{d \alpha}{f(\alpha)}=g(\alpha)=\frac{A}{\beta} \int_{T_{0}}^{T} \exp \left(-\frac{E_{a}}{R T}\right) d T$

If $T_{0}$ is below the temperature where the decomposition rate cannot be measured, the lower boundary of the integral form disappears. lows.

If $X=\left(-\frac{E_{a}}{\text { RT }}\right)$, Eq. (9) can be rearranged to give Eq. (10), as fol-

$g(\alpha)=\left(\frac{\mathrm{AE} a}{\beta R}\right)\left\{-\frac{\exp ^{X}}{X}+\int_{0}^{\infty}\left(\frac{\exp ^{X}}{X}\right) d X\right\}=\left(\frac{\mathrm{AE} a}{\beta R}\right)^{p(X)}$

where $p(X)$ is the temperature integral. This integral does not have an exact analytical solution (Balogun et al., 2014; Flynn, 1983).

Numerous kinetic methods have been derived from Eq. (8). Generally, these can be classified into integral methods, such as those of Ozawa (Ozawa, 1965) and Flynn and Wall (Flynn and Wall, 1966; Flynn, 1983), and differential methods such as those of Friedman (Friedman, 1964) and Kissinger (Kissinger, 1957). The methods of Flynn-Wall-Ozawa (FWO) and Kissinger were used for the calculation of kinetic parameters in the present study.

\subsubsection{Method of Flynn-Wall-Ozawa (FWO)}

The FWO method is based on an integral isoconversional method (Flynn and Wall, 1966; Ozawa, 1965) and is one of the remarkable model-free methods generally used for the determination of the kinetic parameters (Ozawa, 1965). The FWO method uses Doyle's empirical approximation (Doyle, 1965) of the temperature integral in Eq. (10) as described by Eq. (11).

$\log p(X) \cong-2.315+0.4567 X$
After applying the logarithm on Eq. (10) and then inserting into Eq. (11) gives the FWO expression shown in Eq. (12).

$\log \beta=\log \left(\frac{\mathrm{AE}}{g(\alpha) R}\right)-2.315-0.4567\left(\frac{E_{a}}{\mathrm{RT}}\right)$

Hence, the estimated activation energy of Arrhenius $\left(E_{\mathrm{a}}\right)$ can be calculated as described by Eq. (13).

$E_{\mathrm{a}}=-\left(\frac{R}{0.4567}\right) \frac{\Delta \log \beta}{\Delta(1 / T)}$

where $\beta\left(\mathrm{K} \mathrm{min}^{-1}\right)$ is the heating rate, $E_{a}\left(\mathrm{~kJ} \mathrm{~mol}^{-1}\right)$ is the estimated activation energy of Arrhenius, $R$ is the ideal gas constant $\left(8.314 \mathrm{~J} \mathrm{~K}^{-1} \mathrm{~mol}^{-1}\right)$, and $T(\mathrm{~K})$ is the absolute temperature at conversion ( $\alpha$ ). A plot of $\log \beta$ against $1 / T$ for each conversion $(\alpha)$ should result in a straight line. The least-squares method was adopted to fit each straight line and obtain the slope, $\Delta(\log \beta) / \Delta(1 / T)$.

\subsubsection{Kinetic method of Kissinger}

The Kissinger method is based on a differential isoconversional method and is also used to obtain kinetic parameters such as the activation energy of Arrhenius, $E_{a}$, and the reaction order, $n$. Assuming $f(\alpha)=(1-\alpha)^{n}$, as described in Eq. (14).

$\frac{d \alpha}{d T}=\left(\frac{A}{\beta}\right) e^{\left(-\frac{E_{a}}{\mathrm{RT}}\right)}(1-\alpha)^{n}$

where $n$ is the reaction order.

In the Kissinger method the activation energy is derived from the temperature $\left(T_{\mathrm{m}}\right)$ at which the maximum reaction rate (DTG peak) occurs and the reaction order from the shape of the weight loss-time curve (Kissinger, 1957; Jiang et al., 2010). The activation energy, $E_{a}$, is determined by plotting $\ln \left(\beta / T_{\mathrm{m}}{ }^{2}\right)$ against $1 / T_{\mathrm{m}}$, where 

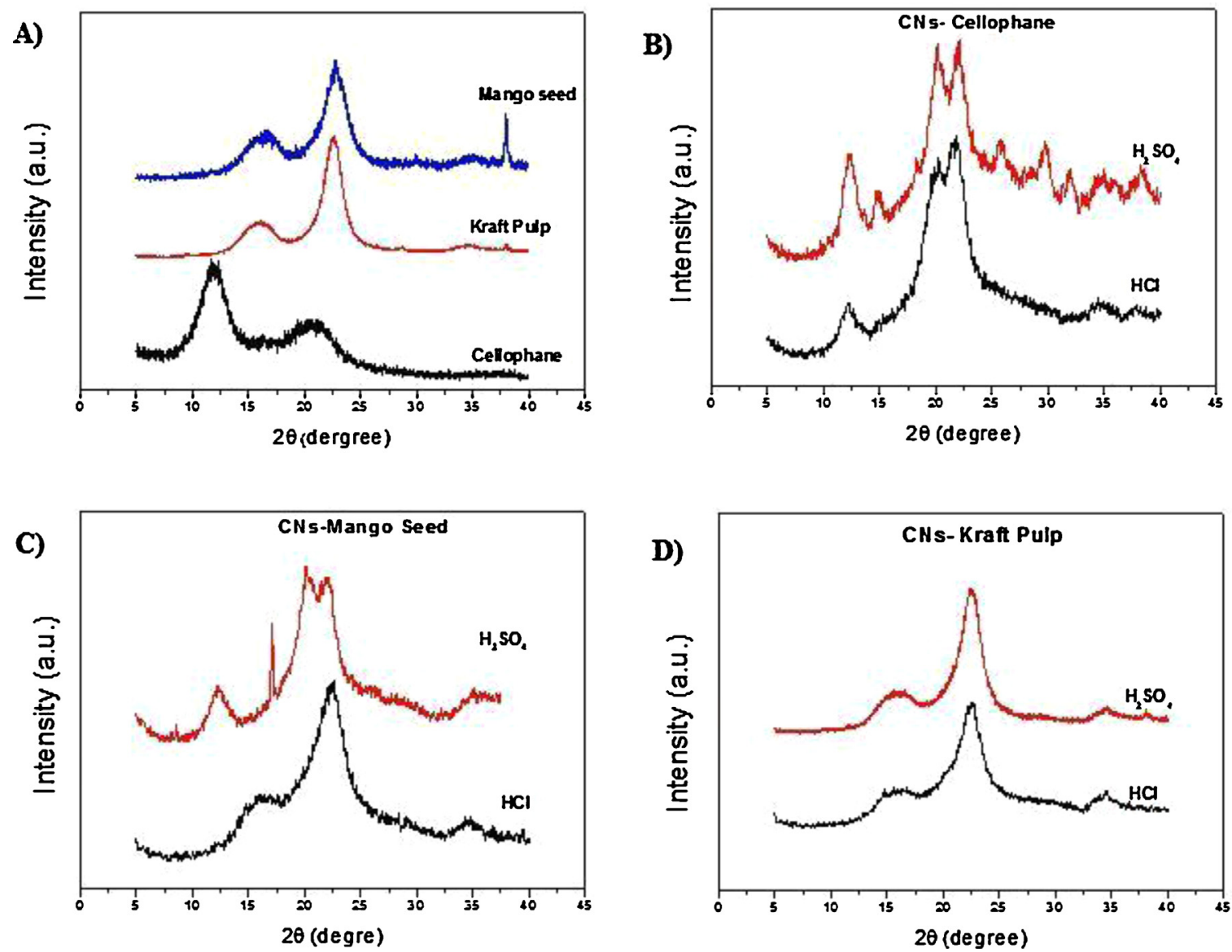

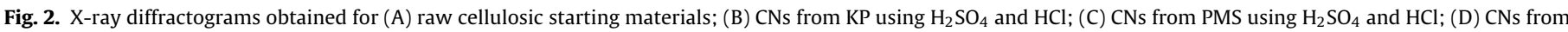
CELL using $\mathrm{H}_{2} \mathrm{SO}_{4}$ and $\mathrm{HCl}$.

the slope, $\Delta\left[\ln \left(\beta / T_{\mathrm{m}}^{2}\right)\right] / \Delta\left(1 / T_{\mathrm{m}}\right)$, is equal to $-E_{\mathrm{a}} / R$. The reaction order, $n$, is calculated using Eq. (15).

$n=1.26 S^{\frac{1}{2}}$

where $S$, the shape index, is defined by Eq. (16). The value of $S$ can be determined from the time derivative of the DTG curve (second derivative of the weight loss-time curve) (Eq. (16)).

$S=\mid \frac{\left(\frac{d^{2} \alpha}{d t^{2}}\right)_{1}}{\left(\frac{d^{2} \alpha}{d t^{2}}\right)_{2}}$

where 1 and 2 refer to the values of the derivatives at the inflection points, i.e., where $d^{3 \alpha} / d t^{3}=0$.

The pre-exponential factor, $A$, can be calculated by inserting the values of $n$ and $E_{\mathrm{a}}$ in Eq. (14) and solving it.

\section{Results and discussion}

When hydrochloric acid was used to extract CNs, nanocrystals with limited dispersion in water solution were obtained, since these particles tend to aggregate through extensive hydrogen bonding (Filson et al., 2009). On the other hand, when sulphuric acid was used to extract $\mathrm{CNs}$, reactions between the sulphate and hydroxyl groups occur which allow the formation of negatively charged sulphate esters. The presence of the negative charges on the cellulose nanocrystals' surfaces generates electrostatic repulsion between nanoparticles that facilitates their dispersion in water, thus leading to the formation of stable aqueous dispersions (Lima and Borsali, 2004; Beck-Candanedo et al., 2005; Peng et al.,
Table 1

Values of sulphur content (SC), zeta potential (ZP), degree of polymerization (DP) and crystallinity index (CrI) for the different samples of CNs extracted.

\begin{tabular}{llccl}
\hline Sample/type of acid & $\mathrm{SC}(\%)$ & $\mathrm{DP}$ & $\mathrm{ZP}(\mathrm{mV})$ & $\mathrm{CrI}(\%)$ \\
\hline $\mathrm{CELL}$ & - & - & - & 61 \\
$\mathrm{CELL}-\mathrm{HCl}$ & 0.93 & 72 & -18.8 & 67 \\
$\mathrm{CELL}-\mathrm{H}_{2} \mathrm{SO}_{4}$ & 3.49 & 78 & -29.2 & 68 \\
$\mathrm{PMS}$ & - & - & - & 66 \\
$\mathrm{PMS}-\mathrm{HCl}$ & 0.93 & 138 & -16.4 & 74 \\
$\mathrm{PMS}-\mathrm{H}_{2} \mathrm{SO}_{4}$ & 3.37 & 78 & -24.4 & 82 \\
$\mathrm{KP}$ & - & - & - & 82 \\
$\mathrm{KP}-\mathrm{HCl}$ & 0.98 & 102 & -17.0 & 71 \\
$\mathrm{KP}-\mathrm{H}_{2} \mathrm{SO}_{4}$ & 3.14 & 107 & -30.3 & 79 \\
\hline
\end{tabular}

2011). This behaviour results in interesting and important optical properties (de Mesquita, 2012). Fig. 1 shows the difference between the suspensions obtained by acid hydrolysis using $\mathrm{H}_{2} \mathrm{SO}_{4}$ and $\mathrm{HCl}$. Interestingly, immediately after the sonication process, all suspensions were found to be homogeneous and well dispersed. However, as time passed, depending on the presence or absence of surface groups in the nanocrystals' surface, these aggregated together in the case of nanocrystals extracted using $\mathrm{HCl}$.

Table 1 shows the sulphur content, zeta potential, degree of polymerization and crystallinity index for the different samples of CNs extracted using $\mathrm{H}_{2} \mathrm{SO}_{4}$ and $\mathrm{HCl}$. As shown in Table $1 \mathrm{CNs}$ extracted using $\mathrm{H}_{2} \mathrm{SO}_{4}$ presented a greater amount of sulphur in their composition, which can be related to the presence of sulphate groups on their surface. The presence of sulphate groups resulted in a negative net charge on the cellulose nanocrystals extracted with sulphuric acid, as evidenced by the zeta potential. These results 

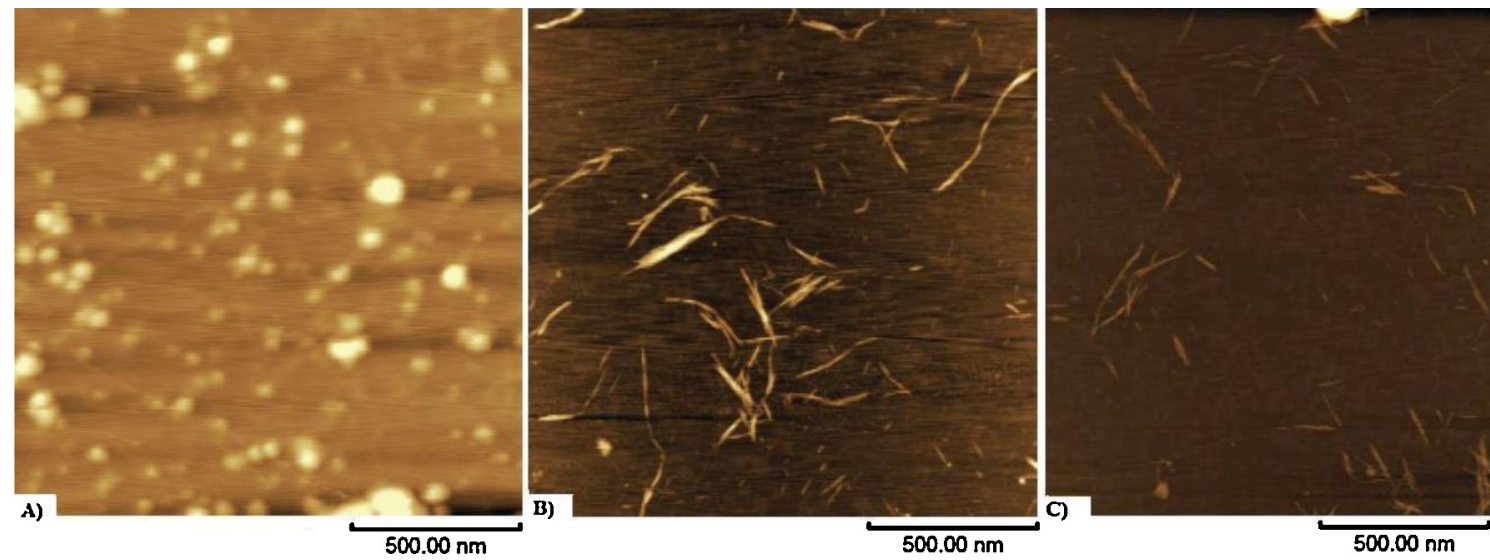

Fig. 3. AFM images of CNs extracted with $\mathrm{HCl}$; (A) CELL; (B) PMS; (C) KP.
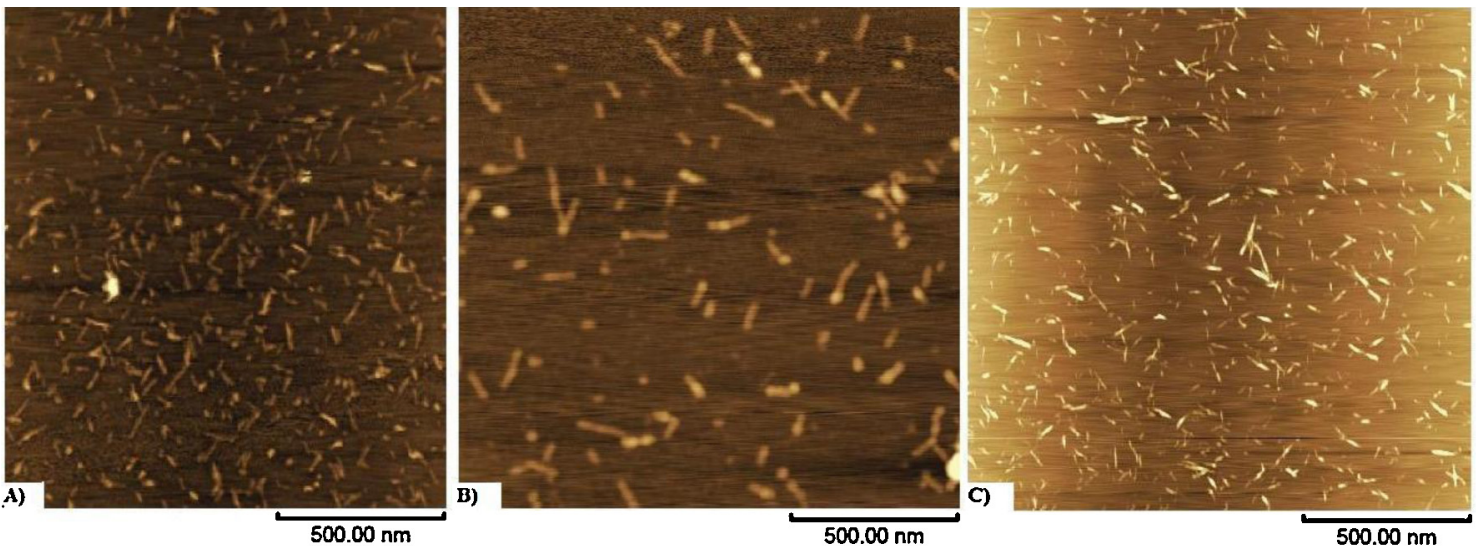

Fig. 4. AFM images of CNs extracted with $\mathrm{H}_{2} \mathrm{SO}_{4}$; (A) CELL; (B) PMS; (C) KP.

confirm the incorporation of sulphate groups on the CNs after extraction with $\mathrm{H}_{2} \mathrm{SO}_{4}$ and that the acid hydrolysis conditions used resulted in homogeneous and stable aqueous suspensions due to electrostatic repulsion.

\subsection{X-ray diffraction (XRD)}

The X-ray diffraction patterns for the different samples and conditions of acid hydrolysis are shown in Fig. 2 as well as the unhydrolyzed starting materials.

In the XRD patterns it is possible to notice that the unhydrolyzed materials have a predominance of crystalline domains typical of cellulose I in the case of Kraft pulp and mango seeds, which is verified by the presence of peaks at $2 \theta=15^{\circ}$ (plane $1-10$ ), $22.5^{\circ}$ (plane 200 ) and $34^{\circ}$ (plane 004 ), while cellophane exhibited crystalline domains typical of regenerated cellulose, or cellulose type II, which can be seen by the peaks at $2 \theta=12^{\circ}$ (plane $1-10$ ) and $20^{\circ}$ (plane 110 ) (French, 2014).

XRD diffractograms of the nanocrystals extracted from KP using both acids and nanocrystals from PMS extracted with $\mathrm{HCl}$ exhibited profiles of cellulose I, while nanocrystals extracted from CELL using both acids and nanocrystals extracted from PMS using $\mathrm{H}_{2} \mathrm{SO}_{4}$ showed profiles of cellulose II. Table 1 shows the crystallinity index of each sample calculated using Eqs. (3) and (4).

As can be seen in Table 1, a decrease was observed in the crystallinity index ( $\mathrm{CrI}$ ) of $\mathrm{CNs}$ obtained from $\mathrm{KP}$ in relation to the unhydrolyzed starting material. This behavior can be attributed to partial dissolution of the sample during the acid hydrolysis of cellulose (Jayme and Lang, 1963). All other CNs samples (PMS and CELL) exhibited CrI values greater than those of the starting materials, which is attributed to the removal of amorphous regions from the cellulose (de Mesquita, 2012). Through diffractograms it was observed that acid hydrolysis may induce CNs to either retain the initial profile of the sample or transform into another cellulose polymorph. Whether a conversion occurs or not depends on various conditions such as acid concentration, hydrolysis time, and the temperature ratio between the acid and the starting material, among others (Sèbe et al., 2012). Cellulose II can be obtained from cellulose I by treatment with aqueous sodium hydroxide (mercerization) or by dissolution of cellulose and subsequent precipitation/regeneration in different solvents (O'sullivan, 1997), including concentrated sulphuric acid. The large difference between cellulose I and II arises from the hydrogen bonding between the cellulose chains, where cellulose II has an antiparallel orientation between the chains due to changes in its hydrogen bond system. This has a direct influence on the structure of the crystal lattice in the cellulose, as demonstrated by X-ray diffraction (de Souza, 2009).

\subsection{Atomic force microscopy (AFM)}

Fig. 3 shows AFM images of the various sources of CNs extracted by acid hydrolysis using $\mathrm{HCl}$. The AFM images showed that CNs extracted from KP and PMS appeared to be cylindrical in shape, while the CNs extracted from CELL showed a spherical shape. The vast majority of CNs extracted by acid hydrolysis result in crystals with cylindrical shapes (Beck-Candanedo et al., 2005). However, the conditions under which high concentrations of acid were used 

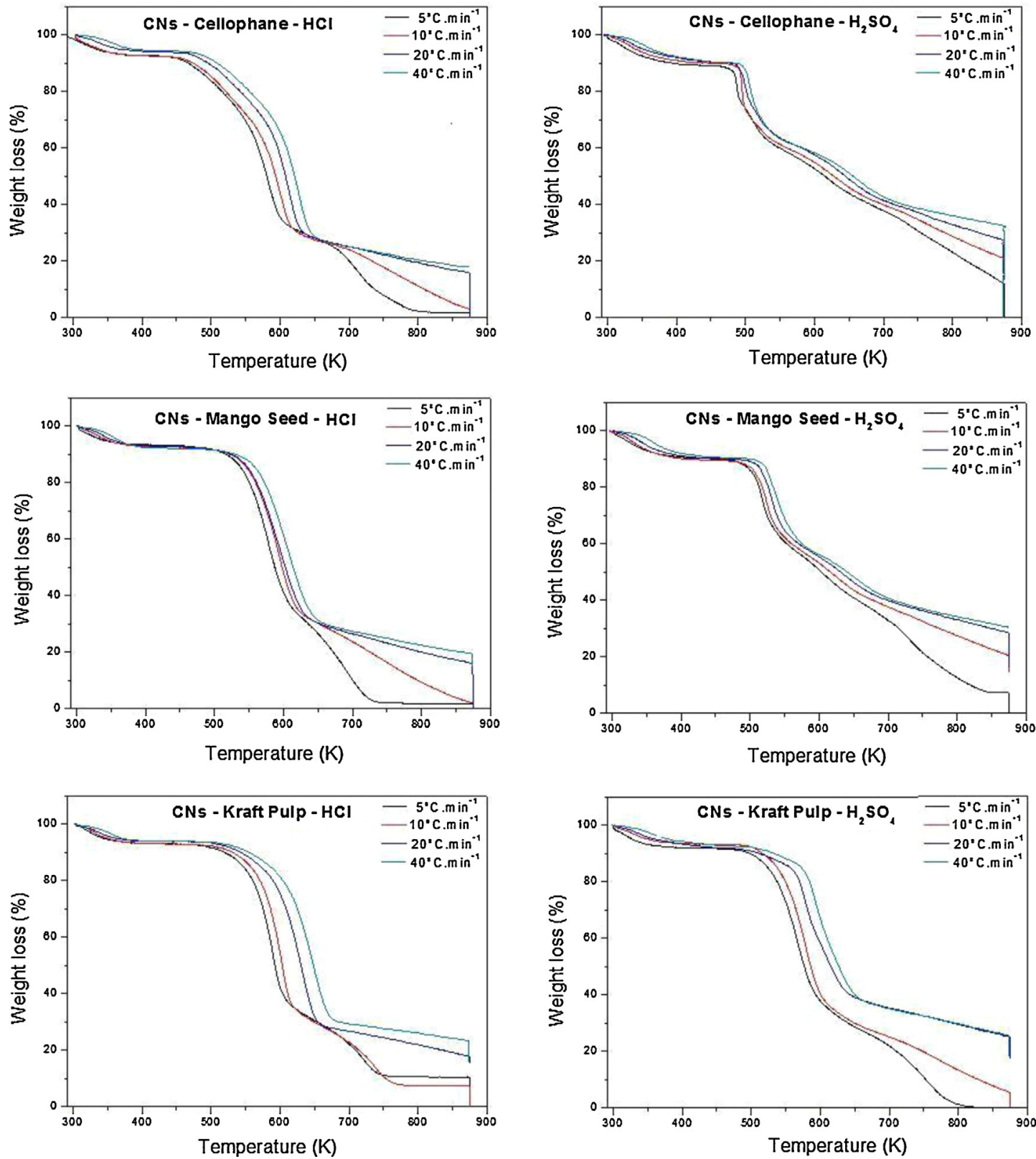

Fig. 5. TG curves for cellulose nanocrystals (CNs) extracted from different samples (CELL, PMS and $\mathrm{KP}$ ) using $\mathrm{H}_{2} \mathrm{SO}_{4}$ and $\mathrm{HCl}$.

Table 2

Thermal decomposition temperatures, $T_{\mathrm{i}}, T_{\mathrm{f}}, T_{\mathrm{m}}$, and $T_{\text {onset }}$ for different $\mathrm{CNs}$ prepared using $\mathrm{HCl}$ and $\mathrm{H}_{2} \mathrm{SO}_{4}$ obtained at a heating rate of $10{ }^{\circ} \mathrm{C}$ min ${ }^{-1}$.

\begin{tabular}{|c|c|c|c|c|c|c|c|c|c|}
\hline Type of CN & Type of acid & $T_{\mathrm{i}}(\mathrm{K})$ & $T_{\mathrm{f}}(\mathrm{K})$ & $T_{\mathrm{m}}(\mathrm{K})$ & $T_{\text {onset }}(\mathrm{K})$ & $T_{\mathrm{i}}\left({ }^{\circ} \mathrm{C}\right)$ & $T_{\mathrm{f}}\left({ }^{\circ} \mathrm{C}\right)$ & $T_{\mathrm{m}}\left({ }^{\circ} \mathrm{C}\right)$ & $T_{\text {onset }}\left({ }^{\circ} \mathrm{C}\right)$ \\
\hline \multirow[t]{2}{*}{ PMS } & $\mathrm{HCl}$ & 515.9 & 631.7 & 581.6 & 537.1 & 242.7 & 358.6 & 308.4 & 263.9 \\
\hline & $\mathrm{H}_{2} \mathrm{SO}_{4}$ & 479.3 & 527.4 & 560.4 & 504.3 & 206.2 & 254.3 & 287.2 & 231.2 \\
\hline \multirow[t]{2}{*}{ PK } & $\mathrm{HCl}$ & 558.4 & 639.3 & 602.8 & 566.8 & 285.3 & 366.2 & 329.6 & 293.6 \\
\hline & $\mathrm{H}_{2} \mathrm{SO}_{4}$ & 494.7 & 647.2 & 585.4 & 535.0 & 221.5 & 374.1 & 312.2 & 261.9 \\
\hline \multirow[t]{2}{*}{ CELL } & $\mathrm{HCl}$ & 519.8 & 649.1 & 596.9 & 477.3 & 246.7 & 376.0 & 323.8 & 204.1 \\
\hline & $\mathrm{H}_{2} \mathrm{SO}_{4}$ & 473.5 & 544.8 & 492.8 & 490.9 & 200.3 & 271.7 & 219.6 & 217.8 \\
\hline
\end{tabular}

in this hydrolysis combined with high temperature and time may result in CNs with a spherical shape (Wang and Sain, 2007). Those $\mathrm{CNs}$ extracted from CELL using $\mathrm{HCl}$ resulted in crystals with an average length of $40.90 \pm 11.63 \mathrm{~nm}$, average diameter of $3.85 \pm 1.23 \mathrm{~nm}$ and aspect ratio of $11.57 \pm 4.87 \mathrm{~nm}$. CNs extracted from PMS exhibited an average length of $153 \pm 48.76 \mathrm{~nm}$, an average diameter of $5.09 \pm 3.09 \mathrm{~nm}$ and an average aspect ratio of $39.97 \pm 26.50 \mathrm{~nm}$. CNs extracted from KP showed an average length of $155.91 \pm 43.64 \mathrm{~nm}$, an average diameter of $4.71 \pm 1.50 \mathrm{~nm}$ and an average aspect ratio of $36.69 \pm 16.02 \mathrm{~nm}$.

Fig. 4 shows AFM images of the $\mathrm{CNs}$ obtained by hydrolysis using $\mathrm{H}_{2} \mathrm{SO}_{4}$. The CNs extracted from CELL using $\mathrm{H}_{2} \mathrm{SO}_{4}$ showed an average length of $123.89 \pm 24.98 \mathrm{~nm}$, an average diameter of $4.61 \pm 1.73 \mathrm{~nm}$ and an average aspect ratio of $31.25 \pm 14.93 \mathrm{~nm}$. CNs extracted from PMS showed an average length of $123 \pm 22.14 \mathrm{~nm}$, an average diameter of $4.59 \pm 2.19 \mathrm{~nm}$ and an average aspect ratio 
Table 3

Pre-exponential factor and activation energy for all the cellulose nanocrystals calculated by the FWO method.

\begin{tabular}{|c|c|c|c|c|c|c|c|c|c|c|c|}
\hline \multicolumn{2}{|l|}{ CELL-HCl } & \multicolumn{2}{|l|}{ CELL- $\mathrm{H}_{2} \mathrm{SO}_{4}$} & \multicolumn{2}{|l|}{ PMS-HCl } & \multicolumn{2}{|l|}{ PMS- $\mathrm{H}_{2} \mathrm{SO}_{4}$} & \multicolumn{2}{|l|}{$\mathrm{KP}-\mathrm{HCl}$} & \multicolumn{2}{|l|}{$\mathrm{KP}-\mathrm{H}_{2} \mathrm{SO}_{4}$} \\
\hline Conversion $(\alpha)$ & $E_{\mathrm{a}}\left(\mathrm{kJ} \mathrm{mol}^{-1}\right)$ & Conversion $(\alpha)$ & $E_{\mathrm{a}}\left(\mathrm{kJ} \mathrm{mol}^{-1}\right)$ & Conversion $(\alpha)$ & $E_{\mathrm{a}}\left(\mathrm{kJ} \mathrm{mol}^{-1}\right)$ & Conversion $(\alpha)$ & $E_{\mathrm{a}}\left(\mathrm{kJ} \mathrm{mol}^{-1}\right)$ & Conversion $(\alpha)$ & $E_{\mathrm{a}}\left(\mathrm{kJ} \mathrm{mol}^{-1}\right)$ & Conversion $(\alpha)$ & $E_{\mathrm{a}}\left(\mathrm{kJ} \mathrm{mol}^{-1}\right)$ \\
\hline 0.18 & 178.03 & 0.18 & 55.44 & 0.18 & 301.94 & 0.18 & 186.47 & 0.17 & 187.85 & 0.2 & 156.34 \\
\hline 0.2 & 180.89 & 0.2 & 57.43 & 0.2 & 306.73 & 0.2 & 192.05 & 0.19 & 176.32 & 0.22 & 152.58 \\
\hline 0.22 & 187.21 & 0.22 & 59.30 & 0.22 & 307.02 & 0.22 & 251.67 & 0.21 & 165.98 & 0.24 & 154.94 \\
\hline 0.24 & 198.01 & 0.24 & 60.55 & 0.24 & 308.01 & 0.24 & 258.24 & 0.23 & 157.89 & 0.26 & 155.74 \\
\hline 0.26 & 205.28 & 0.26 & 60.87 & 0.26 & 308.81 & 0.26 & 343.11 & 0.25 & 151.13 & 0.28 & 158.52 \\
\hline 0.28 & 216.90 & 0.28 & 61.81 & 0.28 & 311.43 & 0.28 & 395.62 & 0.27 & 147.11 & 0.3 & 162.73 \\
\hline 0.3 & 227.55 & 0.3 & 61.98 & 0.3 & 311.87 & 0.3 & 410.50 & 0.29 & 142.35 & 0.32 & 166.11 \\
\hline 0.32 & 243.55 & 0.32 & 62.99 & 0.32 & 312.51 & 0.32 & 410.55 & 0.31 & 139.22 & 0.34 & 170.53 \\
\hline 0.34 & 244.57 & 0.34 & 63.63 & 0.34 & 313.30 & 0.34 & 417.25 & 0.33 & 136.70 & 0.36 & 171.10 \\
\hline 0.36 & 298.78 & 0.36 & 65.61 & 0.36 & 313.95 & 0.36 & 423.51 & 0.35 & 135.66 & 0.38 & 174.08 \\
\hline 0.38 & 352.33 & 0.38 & 67.85 & 0.38 & 314.63 & 0.38 & 425.70 & 0.37 & 133.63 & 0.4 & 175.10 \\
\hline 0.4 & 382.83 & 0.4 & 72.01 & 0.4 & 315.30 & 0.4 & 433.71 & 0.39 & 131.63 & 0.42 & 177.95 \\
\hline 0.42 & 379.93 & 0.42 & 78.41 & 0.42 & 317.02 & 0.42 & 443.60 & 0.41 & 131.01 & 0.44 & 179.61 \\
\hline 0.44 & 373.15 & 0.44 & 93.32 & 0.44 & 317.39 & 0.44 & 453.46 & 0.43 & 130.10 & 0.46 & 182.84 \\
\hline 0.46 & 375.75 & 0.46 & 111.44 & 0.46 & 318.63 & 0.46 & 460.29 & 0.45 & 128.47 & 0.48 & 184.30 \\
\hline 0.48 & 373.34 & 0.48 & 145.92 & 0.48 & 319.24 & 0.48 & 484.68 & 0.47 & 127.33 & 0.5 & 188.87 \\
\hline 0.5 & 366.64 & 0.5 & 192.30 & 0.5 & 320.79 & 0.5 & 511.61 & 0.49 & 126.62 & 0.52 & 191.72 \\
\hline 0.52 & 379.59 & 0.52 & 260.12 & 0.52 & 324.95 & 0.52 & 524.41 & 0.51 & 125.32 & 0.54 & 192.57 \\
\hline 0.54 & 376.71 & & & 0.54 & 333.31 & 0.54 & 582.20 & 0.53 & 125.88 & 0.56 & 194.15 \\
\hline 0.56 & 396.69 & & & 0.56 & 339.03 & 0.56 & 778.84 & 0.55 & 124.92 & 0.58 & 209.90 \\
\hline 0.58 & 411.74 & & & 0.58 & 350.97 & & & 0.57 & 124.18 & 0.6 & 220.14 \\
\hline \multirow[t]{4}{*}{0.6} & 428.12 & & & & & & & 0.59 & 125.47 & 0.62 & 239.61 \\
\hline & & & & & & & & 0.61 & 125.37 & 0.64 & 269.85 \\
\hline & & & & & & & & 0.63 & 127.69 & & \\
\hline & & & & & & & & 0.65 & 128.62 & & \\
\hline
\end{tabular}



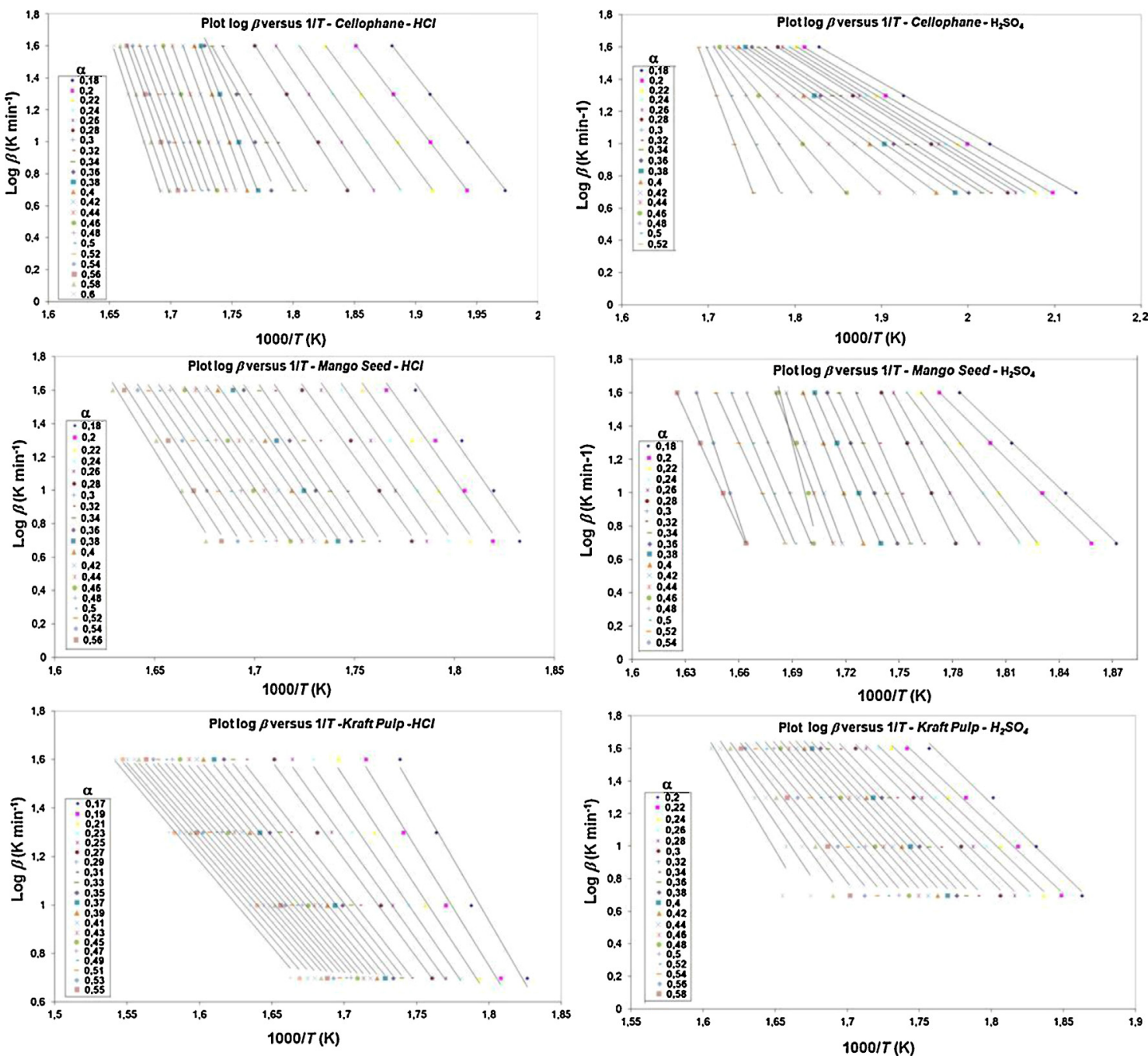

Fig. 6. Plots of $\log \beta$ versus 1000/T for different samples of CNs (CELL, PMS and KP) obtained using $\mathrm{H}_{2} \mathrm{SO}_{4}$ and $\mathrm{HCl}$ at different conversions $(\alpha)$.

of $34.07 \pm 18.60 \mathrm{~nm}$. CNs extracted from KP showed an average length of $189.41 \pm 57.74 \mathrm{~nm}$, an average diameter of $5.46 \pm 1.99 \mathrm{~nm}$ and an average aspect ratio of $41.18 \pm 22.49 \mathrm{~nm}$.

The CNs that showed profiles typical of cellulose type II presented an average length and width substantially smaller than those comprised of cellulose type I. This same behaviour was reported by Sèbe and collaborators (Sèbe et al., 2012). Additionally, as can be seen in Table 1 , the CNs samples with the profile of cellulose I have higher DP values when compared with the CNs samples with the profile of cellulose II. This corroborates the results for the lengths of the CNs determined by AFM.

To determine the exact dimensions of CNs is a complicated task because of the specific limitations of the different analytical methods adopted. In the case of AFM, tip/sample broadening represents the main limitation, resulting in an overestimation of cellulose nanocrystal dimensions. Since the $\mathrm{CNs}$ are assumed to be cylindrical in shape, the height of the CNs was taken to be equivalent to the diameter, to compensate for image widening due to the convolution of the tip and the particle (Beck-Candanedo et al., 2005; Kvien et al., 2005; Flauzino Neto et al., 2013). However, tip-broadening effects also cause errors in length measurements, but this is unavoidable (Beck-Candanedo et al., 2005).

\subsection{Thermogravimetric analysis (TGA)}

The thermal decomposition for all cellulose nanocrystals followed a similar behaviour observed for the thermal decomposition of celluloses reported in the literature (Poletto et al., 2011; Gurgel et al., 2012). TG curves for all cellulose nanocrystals obtained in this study are shown in Fig. 5. It can be noticed that for all CNs, the profiles of weight loss essentially exhibited three main decomposition events. The first main decomposition event, which occurred at temperatures below $100^{\circ} \mathrm{C}$, was related to the evaporation of adsorbed and bound water and/or compounds of low molecular weight adsorbed on the nanocrystals' surface and represented $\sim 10 \%$ of the total weight loss on average of the samples. For all cellulose nanocrystals, the initial weight loss was followed by a plateau that prolonged to the start of the second main decomposition event. The second main decomposition event corresponded to cellulose degradation, which consisted of several concurrent processes such as depolymerization, dehydration and decomposition of glycosidic units (Roman and Winter, 2004). The third main decomposition event was attributed to the oxidation and breakdown of charred residues to form gaseous products of low molecular weight (Roman and Winter, 2004; Teixeira et al., 2010). 

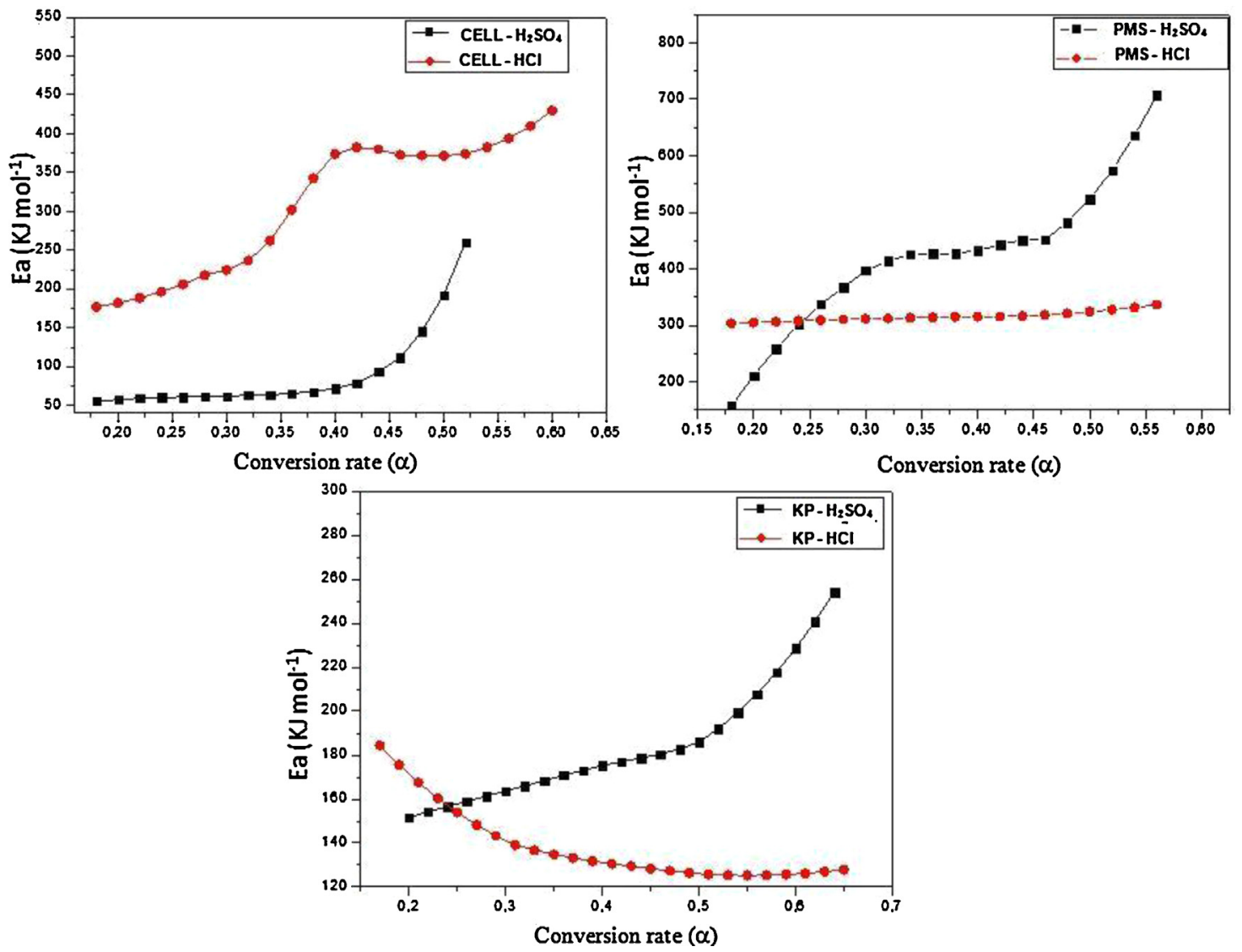

Fig. 7. Plots for activation energy ( $\left.E_{\mathrm{a}}\right)$ versus conversion rate $(\alpha)$ for thermal decomposition of different $\mathrm{CNs}$ extracted using $\mathrm{H}_{2} \mathrm{SO}_{4}$ and $\mathrm{HCl}_{\text {. }}$

Table 4

Pre-exponential factor $(A)$, activation energy $\left(E_{a}\right)$ and reaction order $(n)$ calculated by the Kissinger method.

\begin{tabular}{|c|c|c|c|c|c|c|c|c|c|}
\hline \multicolumn{5}{|l|}{ CELL-HCl } & \multicolumn{5}{|l|}{ CELL- $\mathrm{H}_{2} \mathrm{SO}_{4}$} \\
\hline$\beta\left(\mathrm{K} \mathrm{min}^{-1}\right)$ & $S$ & $n$ & $E_{\mathrm{a}}\left(\mathrm{kJ} \mathrm{mol}^{-1}\right)$ & $\ln A$ & $\beta\left(\mathrm{Kmin}^{-1}\right)$ & $S$ & $n$ & $E_{\mathrm{a}}\left(\mathrm{kJ} \mathrm{mol}^{-1}\right)$ & $\ln A$ \\
\hline 5 & 0.971 & 1.242 & 134.66 & 8.444 & 5 & 0.68 & 1.039 & 145.13 & 24.476 \\
\hline 10 & 0.667 & 1.029 & & & 10 & 0.329 & 0.723 & & \\
\hline 20 & 1.19 & 1.375 & & & 20 & 1.923 & 1.747 & & \\
\hline 40 & 0.774 & 1.109 & & & 40 & 1.263 & 1.416 & & \\
\hline \multicolumn{5}{|l|}{ PMS-HCl } & \multicolumn{5}{|l|}{ PMS- $\mathrm{H}_{2} \mathrm{SO}_{4}$} \\
\hline$\beta\left(\mathrm{K} \mathrm{min}^{-1}\right)$ & $S$ & $n$ & $E_{\mathrm{a}}\left(\mathrm{kJ} \mathrm{mol}^{-1}\right)$ & $\ln A$ & $\beta\left(\mathrm{Kmin}^{-1}\right)$ & $S$ & $n$ & $E_{\mathrm{a}}(\mathrm{kJ} \mathrm{mol}-1)$ & $\ln A$ \\
\hline 5 & 0.974 & 1.243 & 202.42 & 19.363 & 5 & 1.208 & 1.385 & 275.8 & 53.109 \\
\hline 10 & 1.045 & 1.288 & & & 10 & 1.2 & 1.38 & & \\
\hline 20 & 0.882 & 1.184 & & & 20 & 1 & 1.26 & & \\
\hline 40 & 0.875 & 1.179 & & & 40 & 1.583 & 1.585 & & \\
\hline \multicolumn{5}{|l|}{$\mathrm{KP}-\mathrm{HCl}$} & \multicolumn{5}{|l|}{$\mathrm{KP}-\mathrm{H}_{2} \mathrm{SO}_{4}$} \\
\hline$\beta\left(\mathrm{K} \mathrm{min}^{-1}\right)$ & $S$ & $n$ & $E_{\mathrm{a}}\left(\mathrm{kJ} \mathrm{mol}^{-1}\right)$ & $\ln A$ & $\beta\left(\mathrm{K} \mathrm{min}^{-1}\right)$ & $S$ & $n$ & $E_{\mathrm{a}}\left(\mathrm{kJ} \mathrm{mol}^{-1}\right)$ & $\ln A$ \\
\hline 5 & 0.492 & 0.884 & 102.23 & 9.693 & 5 & 0.855 & 1.165 & 140.67 & 19.02 \\
\hline 10 & 0.511 & 0.901 & & & 10 & 0.7 & 1.054 & & \\
\hline 20 & 0.519 & 0.908 & & & 20 & 1.506 & 1.547 & & \\
\hline 40 & 0.681 & 1.04 & & & 40 & 0.915 & 1.205 & & \\
\hline
\end{tabular}

The onset temperature, $T_{\text {onset }}$, which is related to the thermal stability of a sample, was lower for cellulose nanocrystals (PMS and $\mathrm{KP}$ ) extracted using $\mathrm{H}_{2} \mathrm{SO}_{4}$ in comparison with those extracted using $\mathrm{HCl}$, with exception for cellulose nanocrystals from CELL that exhibited the opposite behavior. A low thermal stability is expected for cellulose nanocrystals containing sulphate groups, since these groups may increase the rate of cellulose dehydration reactions (Roman and Winter, 2004). This occurs because the incorporation of sulphate groups onto the cellulose surface after acid hydrolysis has a catalytic effect on its thermal degradation. Another effect that has been reported is the replacement of cellulose hydroxyl groups by sulphate groups, which leads to a decrease in the activation energy (Teixeira et al., 2010).

As can be seen from Table 2, the initial decomposition temperature, $T_{\mathrm{i}}$, onset decomposition temperature, $T_{\text {onset }}$, and temperature where the decomposition rate reaches its maximum, $T_{\mathrm{m}}$, were smaller for $\mathrm{CNs}$ prepared using $\mathrm{H}_{2} \mathrm{SO}_{4}$ than those prepared using $\mathrm{HCl}$. These results indicate that $\mathrm{CNs}$ prepared using $\mathrm{H}_{2} \mathrm{SO}_{4}$ are less 
CNs - Cellophane - HCI

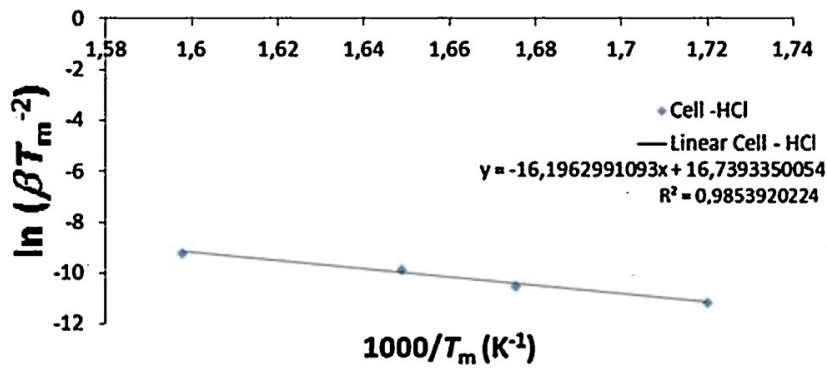

CNs - Mango Seed - $\mathrm{HCl}$

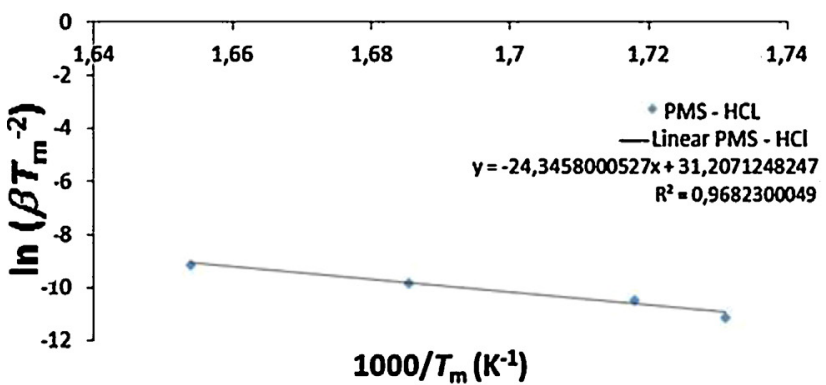

CNs - Kraft Pulp - HCl

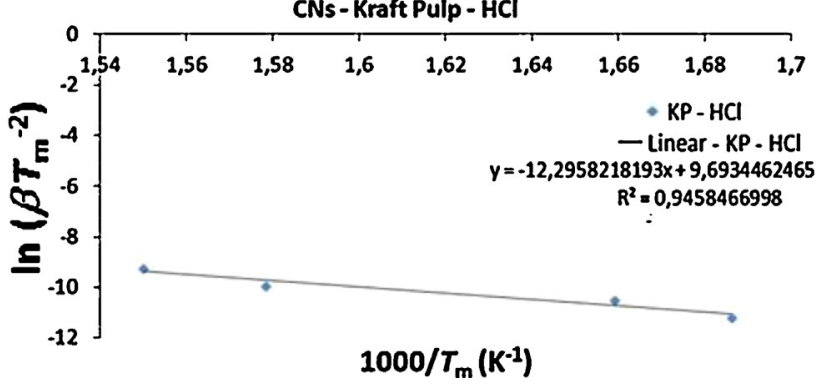

CNs - Cellophane $-\mathrm{H}_{2} \mathrm{SO}_{4}$

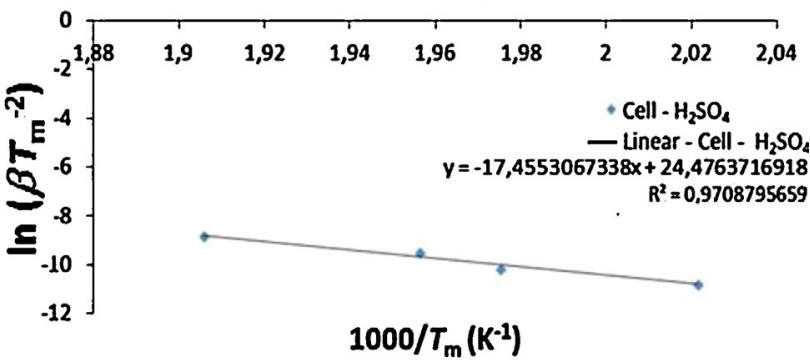

CNs - Mango Seed - $\mathrm{H}_{2} \mathrm{SO}_{4}$
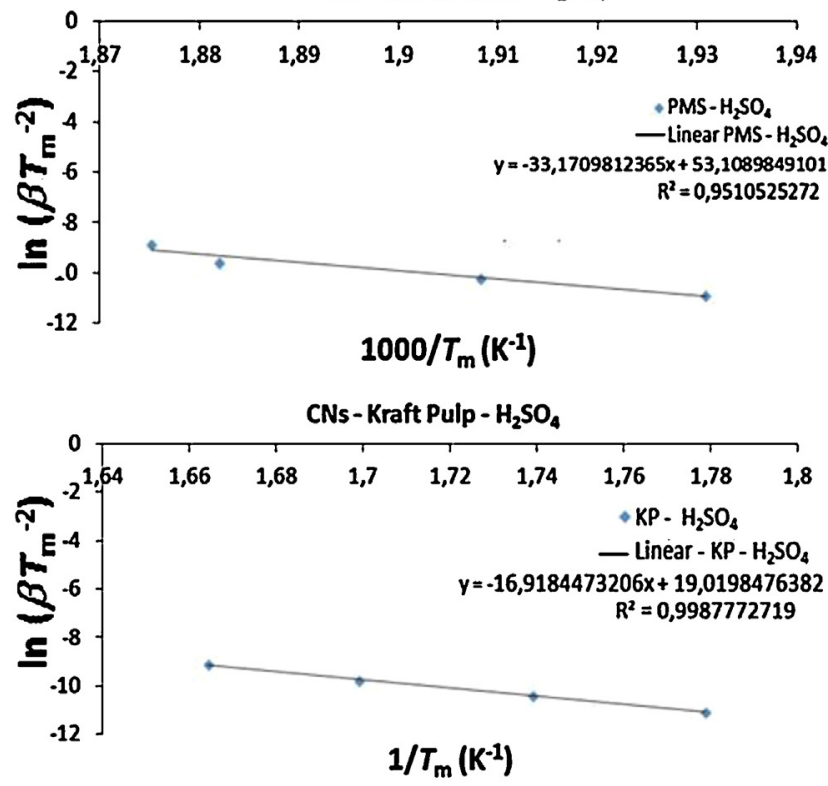

Fig. 8. - Plots of $\ln \left(\beta / T_{\mathrm{m}}{ }^{2}\right)$ against $1000 / T_{\mathrm{m}}$ using the Kissinger method for all cellulose nanocrystals.

resistant to thermal degradation than those prepared using $\mathrm{HCl}$. These findings indicates that $\mathrm{CNs}$ prepared using $\mathrm{HCl}$ are more appropriated to be used as reinforcement for polymers composites since they resist to thermal decomposition until temperatures of approximately $240^{\circ} \mathrm{C}$. Similar conclusions were also found by Jeong and collaborators (Jeong et al., 2010).

\subsubsection{Kinetics results}

In order to obtain the kinetics parameters for the thermal decomposition of cellulose nanocrystals, the conversion $(\alpha)$ was determined according to method described in the theoretical approach (Section 2.8.1). The FWO and Kissinger methods were used to calculate the activation energy $\left(E_{\mathrm{a}}\right)$, the pre-exponential factor $(A)$ and reaction order $(n)$. Fig. 6 shows plots of $\log \beta$ versus $1000 / T$ using FWO method for various values of conversion $(\alpha)$ for all CNs prepared. In all cases, the lines have become nearly parallel, indicating approximate activation energies in different conversions and thus implying the possibility of a simple reaction mechanism (Yao et al., 2008).

The values of activation energy $\left(E_{\mathrm{a}}\right)$ calculated using FWO method for all CNs prepared are shown in Table 3. Fig. 7 shows the plots of the activation energy $\left(E_{\mathrm{a}}\right)$ against conversion $(\alpha)$ for different samples of CNs extracted using $\mathrm{H}_{2} \mathrm{SO}_{4}$ and $\mathrm{HCl}$.

In order to discuss the values of $E_{\mathrm{a}}$ involved in the thermal decomposition of CNs extracted from different sources is necessary to consider the type of cellulose polymorph, DP, CrI, and type of catalyst $\left(\mathrm{H}_{2} \mathrm{SO}_{4}\right.$ or $\left.\mathrm{HCl}\right)$ used to hydrolyse cellulose samples. The CNs extracted from different sources showed different polymorphs of cellulose. CNs from KP extracted using both acids $\left(\mathrm{H}_{2} \mathrm{SO}_{4}\right.$ and $\left.\mathrm{HCl}\right)$ and PMS extracted using $\mathrm{HCl}$ showed profiles of cellulose I, while CNs from PMS extracted using $\mathrm{H}_{2} \mathrm{SO}_{4}$ and CELL extracted using both acids showed profiles of cellulose II. Morgado and Frollini (2011) studied the thermal decomposition kinetics of untreated linters cellulose (cellulose I) and mercerized linters cellulose (cellulose II). They observed that the value of $E_{\mathrm{a}}$ for thermal decomposition of the former was $158 \mathrm{~kJ} / \mathrm{mol}$, while $E_{\mathrm{a}}$ for the latter was $187 \mathrm{~kJ} / \mathrm{mol}$. This means that more energy is required in the thermal decomposition of cellulose II in comparison with cellulose I. This difference may be related to the different orientation of cellulose chains and pattern of hydrogen bonding in cellulose I and II. While cellulose I chains are orientated in parallel and the $-\mathrm{CH}_{2} \mathrm{OH}$ groups of adjacent chains have the same conformation, the cellulose II chains are orientated in antiparallel, with $-\mathrm{CH}_{2} \mathrm{OH}$ groups occupying different positions. Because of these differences, the hydrogen bonds in cellulose II are stronger than those in cellulose I, which result in a higher thermal stability of cellulose II in comparison with cellulose I (Morgado and Frollini, 2011). However, it was verified that for CNs samples, the type of acid had a greater influence than type of cellulose polymorph on $E_{\mathrm{a}}$ for thermal decomposition. Those samples extracted using $\mathrm{H}_{2} \mathrm{SO}_{4}$ showed lower initial $E_{\mathrm{a}}$ than those extracted using $\mathrm{HCl}$, since the introduction of sulphate groups decreased the thermal stability of CNs. It is well known that the mechanism of cellulose decomposition firstly involves dehydration reactions to form anhydrocellulose through either inter- or intra-ring dehydration (Morgado and Frollini, 2011; Scheirs et al., 2001; Roman and Winter, 2004). The introduction of sulphate groups, which are 
well-known dehydration catalysts, facilitates the thermal decomposition of CNs, justifying the initial lower $E_{\mathrm{a}}$ values observed for the samples obtained using $\mathrm{H}_{2} \mathrm{SO}_{4}$ as the catalyst (Roman and Winter, 2004).

Analyzing $E_{\mathrm{a}}$ values involved in the thermal decomposition of each $\mathrm{CN}$ produced from CELL, PMS, and $\mathrm{KP}$ using $\mathrm{H}_{2} \mathrm{SO}_{4}$ and $\mathrm{HCl}$ as the catalysts, it is possible to note that for CNs from CELL the values of DP and $\mathrm{CrI}$ are quite similar (Table 1 ). Therefore, the great difference between $E_{\mathrm{a}}$ values for these $\mathrm{CNs}$ can be attributed to the presence of sulphate groups, which catalyze the dehydration of CNs lowering the value of $E_{\mathrm{a}}$ until conversions closer to 0.40 . In conversions higher than 0.40 , these $\mathrm{CNs}$ seem to follow different decomposition mechanisms as $E_{\mathrm{a}}$ value increases sharply for CELL$\mathrm{H}_{2} \mathrm{SO}_{4}$ in comparison with CELL-HCl. For CNs from PMS, the values of DP and CrI are different. PMS- $\mathrm{HCl}$ has higher DP and smaller $\mathrm{CrI}$ than $\mathrm{PMS}-\mathrm{H}_{2} \mathrm{SO}_{4}$. The values of $E_{\mathrm{a}}$ for $\mathrm{PMS}-\mathrm{H}_{2} \mathrm{SO}_{4}$ are smaller than PMS- $\mathrm{HCl}$ until conversions closer to 0.22 . After conversions higher than 0.25 , the values of $E_{\mathrm{a}}$ for PMS- $\mathrm{H}_{2} \mathrm{SO}_{4}$ are always higher than PMS-HCl. The influences of DP and CrI are not clear since $E_{\mathrm{a}}$ values involved in the thermal decomposition of these $\mathrm{CNs}$ are quite different from $\alpha$ values $>0.25$. For $\mathrm{CNs}$ from KP, KP-HCl has smaller values of DP and $\mathrm{CrI}$ than $\mathrm{KP}-\mathrm{H}_{2} \mathrm{SO}_{4}$. Apart from the influence of sulphur content for $\mathrm{KP}-\mathrm{H}_{2} \mathrm{SO}_{4}$, which decreases the initial values of $E_{\mathrm{a}}$, the smaller values of $\mathrm{DP}$ and $\mathrm{CrI}$ for $\mathrm{KP}-\mathrm{HCl}$ seem to influence the values of $E_{\mathrm{a}}$, lowering them in conversions higher than 0.25 . As the sulphur content, DP, CrI, and type of cellulose polymorph have influence on $E_{\mathrm{a}}$ values for thermal decomposition of CNs, it is difficult to correlate the values of $E_{\mathrm{a}}$ for different $\mathrm{CNs}$ from different sources. It is known that lower values of DP and CrI decrease the value of $E_{\mathrm{a}}$ since a low $\mathrm{CrI}$ favors the dehydration reactions and a low DP favors the depolymerization reactions of cellulose (Bouchard et al., 1989; Bouchard et al., 1990; Gurgel et al., 2012).

Fig. 8 shows the plots of $\ln \left(\beta / T_{\mathrm{m}}{ }^{2}\right)$ against $1000 / T_{\mathrm{m}}$ using the Kissinger method for all CNs prepared. The activation energy $\left(E_{\mathrm{a}}\right)$, pre-exponential factor $(A)$ and reaction order $(n)$ obtained by the Kissinger method are shown in Table 4. Values of $E_{a}$ for thermal decomposition were different for the different hydrolysis conditions. The Kissinger method adopts the value of average activation energy, obtained from the slope in the straight line. This value cannot necessarily represent the value of the global activation energy (Yao et al., 2008). As can be seen in Table 4, all values of $E_{\mathrm{a}}$ for CNs prepared using $\mathrm{HCl}$ as the catalyst were smaller than those for CNs prepared using $\mathrm{H}_{2} \mathrm{SO}_{4}$ as the catalyst. As the value of $E_{\mathrm{a}}$ obtained from Kissinger method is an average value of $E_{\mathrm{a}}$, the abrupt increase of $E_{\mathrm{a}}$ value in conversions higher than $0.425,0.475$, and 0.50 for CELL- $\mathrm{H}_{2} \mathrm{SO}_{4}, \mathrm{PMS}-\mathrm{H}_{2} \mathrm{SO}_{4}$, and $\mathrm{KP}-\mathrm{H}_{2} \mathrm{SO}_{4}$, respectively, contributes to increase the values of $E_{\mathrm{a}}$ for CNs obtained from samples using $\mathrm{H}_{2} \mathrm{SO}_{4}$ as the catalyst.

The values of the reaction order $(n)$ found by the Kissinger method are shown in Table 4. For all samples the order of reaction approximately to the unit. It can be seen from these results that the order of reaction decreased as the degree of polymerization decreased, as reported by Calahorra (Calahorra et al., 1989).

Comparing the values of $E_{a}$ obtained by the two methods, it can be seen that the $E_{a}$ calculated by the FWO method is generally higher than those calculated by the Kissinger method, which simply gives the different parameters adopted by each method (Gurgel et al., 2012).

\section{Conclusions}

Cellulose nanocrystals were obtained from different sources and under different conditions of hydrolysis with success. By X-ray diffraction it was observed that the CNs showed different morphological characteristics. The presence of both cellulose type I and cellulose type II was noted. The CNs showed crystallinity index values ranging from 67 to $82 \%$. The CNs had mostly cylindrical shape, with the exception of $\mathrm{CNs}$ extracted from cellophane using $\mathrm{HCl}$ that showed a circular shape as evidenced by AFM images. The CNs had an average length $(L)$ ranging from 40.90 to $189.41 \mathrm{~nm}$, average diameter $(D)$ ranging from 3.85 to $5.46 \mathrm{~nm}$ and average aspect ratio $(L / D)$ from 11.57 to $41.18 \mathrm{~nm}$. CNs composed of cellulose II had lower DP values than CNs composed of cellulose I. Thermogravimetric analysis was used to investigate the thermal decomposition of all samples of $\mathrm{CNs}$ obtained. The $\mathrm{CNs}$ extracted using $\mathrm{H}_{2} \mathrm{SO}_{4}$ were less thermally stable than those extracted using $\mathrm{HCl}$. The FWO and Kissinger methods were used to determine the kinetic parameters such as activation energy, pre-exponential factor and reaction order. The activation energy $\left(E_{\mathrm{a}}\right)$ calculated by the FWO method was generally higher than that calculated by the Kissinger method. The $E_{\mathrm{a}}$ of cellulose II CNs increased with increasing conversion $(\alpha)$, while in the case of cellulose I CNs the $E_{a}$ remained constant or decreased slightly with $\alpha$. The type of polymorph of cellulose and the acid employed in the $\mathrm{CN}$ extraction affected the thermal degradation kinetics of the CNs.

\section{Acknowledgements}

Authors thank CAPES, CNPq and FAPEMIG for financial support.

\section{References}

Balogun, A.O., Lasode, O.A., McDonald, A.G., 2014. Devolatilization kinetics and pyrolytic analyses of Tectona grandis (teak). Bioresour. Technol. 156, 57-62.

Beck-Candanedo, S., Roman, M., Gray, D.G., 2005. Effect of reaction conditions on the properties and behavior of wood cellulose nanocrystal suspensions. Biomacromolecules 6, 1048-1054.

Bouchard, J., Abatzoglou, N., Chornet, E., Overend, R.P., 1989. Characterization of depolymerized cellulosic residues.1. residues obtained by acid-hydrolysis processes. Wood Sci. Technol. 23, 343-355.

Bouchard, J., Garnier, G., Vidal, P., Chornet, E., Overend, R.P., 1990. Characterization of depolymerized cellulosic residues. 2. residues derived from ethylene-glycol solvolysis of cellulose. Wood Sci. Technol. 24, 159-169.

Calahorra, M.E., Cortázar, M., Eguiazábal, J.I., Guzmán, G.M., 1989. Thermogravimetric analysis of cellulose: effect of the molecular weight on thermal decomposition. J. Appl. Polym. Sci. 37, 3305-3314.

de Mesquita, J.P., 2012. Nanocristais de celulose para preparação de bionanocompósitos com quitosana e carbonos nanoestruturados para aplicações tecnológicas e ambientais. In: Ph.D. Thesis. Universidade Federal de Minas Gerais.

de Rodriguez, N.L.G., Thielemans, W., Dufresne, A., 2006. Sisal cellulose whiskers reinforced polyvinyl acetate nanocomposites. Cellulose 13, 261-270.

de Souza, E.E., 2009. Síntese e caracterização de membranas de celulose regenerada a partir da celulose extraída do bagaço de cana-de-açúcar para produção de cuprofane. In: M.S. Dissertation. Universidade Federal de Uberlândia.

Doyle, C.D., 1965. Series approximations to the equations of the thermogravimetric data. Nature 207, 290-291.

Eichhorn, S.J., Dufresne, A., Aranguren, M., Marcovich, N.E., Capadona, J.R., Rowan, S.J., Weder, C., Thielemans, W., Roman, M., Renneckar, S., Gindl, W., Veigel, S., Keckes, J., Yano, H., Abe, K., Nogi, M., Nakagaito, A., Mangala, A., Simonsen, J., Benigth, A.S., Bismark, A., Berglund, L.A., Peijs, T., 2010. Review: current international research into cellulose nanofibres and nanocomposites. J. Mater. Sci. 45, 1-33.

Filson, P.B., Dawson-Andoh, B.E., 2009. Sono-chemical preparation of cellulose nanocrystals from lignocellulose derived materials. Bioresour. Technol. 100, 2259-2264

Filson, P.B., Dawson-Andoh, B.E., Schwegler-Berry, D., 2009. Enzymatic-mediated production of cellulose nanocrystals from recycled pulp. Green Chem. 11, 1808-1814.

Flauzino Neto, W.P., Silvério, H.A., Dantas, N.O., Pasquini, D., 2013. Extraction and characterization of cellulose nanocrystals from agro-industrial residue - Soy hulls. Ind. Crops Prod. 42, 480-488.

Flynn, J.H., Wall, L.A., 1966. A quick, direct method for the determination of activation energy from thermogravimetric data. J. Polym. Sci. Polym. Lett. 4 323-328.

Flynn, J.H., 1983. The isoconversional method for determination of energy of activation at constant heating rates. J. Therm. Anal. 27, 95-102.

French, A.D., 2014. Idealized powder diffraction patterns for cellulose polymorphs. Cellulose 21, 885-896.

Friedman, H.L.J., 1964. Kinetics of thermal degradation of char-forming plastics from thermogravimetry. Application to phenolic plastic. Polym. Sci. Polym. Sym. 6PC, 183-195. 
Gurgel, L.V.A., Marabezi, K., Ramos, L.A., Curvelo, A.A.S., 2012. Characterization of depolymerized residues from extremely low acid hydrolysis (ELA) of sugarcane bagasse cellulose: Effects of degree of polymerization, crystallinity and crystallite size on thermal decomposition. Ind. Crops Prod. 36, 560-571.

Habibi, Y., Lucia, L.A., Rojas, O.J., 2010. Cellulose nanocrystals: chemistry, self-assembly, and applications. Chem. Rev. 110, 3479-3500.

Jayme, G., Lang, F., 1963. Cellulose solvents. In: Whistler, R.L. (Ed.), Methods in Carbohydrate Chemistry. Academic Press, New York, pp. 75-83.

Jeong, H.D., Yoon, C.R., Lee, J.H., Band, D.S., 2010. Preparation and characterization of cellulose nano-whiskers extracted from microcrystalline cellulose by acid hydrolysis. Elastom. Compos. 45, 51-57.

Jiang, G., Nowakowski, D.J., Bridgwater, A.V., 2010. A systematic study of the kinetics of lignin pyrolysis. Thermochim. Acta 498, 61-66.

Kissinger, H.E., 1957. Reaction kinetics in differential thermal analysis. Anal. Chem. 29, 1702-1706.

Kvien, I., Tanem, B.S., Oksman, K., 2005. Characterization of cellulose whiskers and their nanocomposites by atomic force and electron microscopy. Biomacromolecules 6, 3160-3165.

Lahiji, R.R., Xu, X., Reifenberger, R., Raman, A., Rudie, A., Moon, R.J., 2010. Atomic force microscopy characterization of cellulose nanocrystals. Langmuir 26, 4480-4488.

Li, R., Fei, J., Cai, Y., Li, Y., Feng, J., Yao, J., 2009. Cellulose whiskers extracted from mulberry: a novel biomass production. Carbohydr. Polym. 76, 94-99.

Lima, M.M.S., Borsali, R., 2004. Rodlike cellulose microcrystals: structure, properties, and applications. Macromol. Rapid Commun. 25, 771-787.

Liu, H., Liu, D., Yao, F., Wu, Q., 2010. Fabrication and properties of transparent polymethylmethacrylate/cellulose nanocrystals composites. Bioresour. Technol. 101, 5685-5692.

Martínez-Sanz, M., Lopez-Rubio, A., Lagaron, J.M., 2011. Optimization of the nanofabrication by acid hydrolysis of bacterial cellulose nanowhiskers. Carbohydr. Polym. 85, 228-236.

Moon, R.J., Martini, A., Nairn, J., Simonsen, J., Youngblood, J., 2011. Cellulose nanomaterials review: structure, properties and nanocomposites. Chem. Soc. Ver. 40, 3941-3994

Morgado, D.L., Frollini, E., 2011. Thermal decomposition of mercerized linter cellulose and its acetates obtained from a homogeneous reaction. Polímeros $21,111-117$.

O'sullivan, A.C., 1997. Cellulose: the structure slowly unravels. Cellulose 4, 173-207.

Ozawa, T., 1965. A new method of analyzing thermogravimetric data. Bull. Chem. Soc. Jpn. 38, 1881-1886.

Peng, B.L., Dhar, N., Liu, H.L., Tam, K.C., 2011. Chemistry and applications of nanocrystalline cellulose and its derivatives: a nanotechnology perspective. Can. J. Chem. Eng. 9999, 1-16.
Poletto, M., Pistor, V., Zeni, M., Zaterra, A.J., 2011. Crystalline properties and decompositions kinetcs of cellulose fibers in wood pulp obtained by two pulping processes. Polym. Degrad. Stab. 96, 679-685.

Ramajo-Escalera, B., Espina, A., García, J.R., Sosa-Arnao, J.H., Nebra, A.S., 2006. Model-free kinetics applied to sugarcane bagasse combustion. Thermochim. Acta 448, 111-116.

Revol, J.F., Dietrich, A., Goring, D.A.J., 1987. Effect of mercerization on the crystallite size and cristallinity index in cellulose from different sources. Can. J. Chem. 65, 1724-1725.

Roman, M., Winter, W.T., 2004. Effect of Sulfate groups from sulfuric acid hydrolysis on the thermal degradation behavior of bacterial cellulose. Biomacromolecules 5, 1671-1677.

Samir, M.A.S.A., Alloin, F., Dufresne, A., 2005. Review of recent research into cellulosic whiskers, their properties and their application in nanocomposite field. Biomacromolecules 6, 612-626.

Scheirs, J., Camino, G., Tumiatti, W., 2001. Overview of water evolution during the thermal degradation of cellulose. Eur. Polym. J. 37, 933-942.

Sèbe, G., Ham-Pichavant, F., Ibarboure, E., Koffi, A.L.C., Tingaut, P., 2012 Supramolecular structure characterization of cellulose II nanowhiskers produced by acid hydrolysis of cellulose I substrates. Biomacromolecules 13 570-578.

Segal, L., Creely, J.J., Martin Junior, A.E., Conrad, C.M., 1959. An empirical method for estimating the degree of crystallinity of native cellulose using the X-ray diffractometer. Text. Res. J. 29, 786-794.

Silva, D.J., D’Almeida, M.L.O., 2009. Nanocristais de celulose: cellulose whiskers. O Papel 70, 34-52.

Siqueira, G., Bras, J., Dufresne, A., 2010. Cellulosic bionanocomposites: a review of preparation, properties and applications. Polymers 2, $728-765$.

Teixeira, E.M., Bondancia, T.J., Teodoro, K.B.R., Corrêa, A.C., Marconcini, J.M., Mattoso, L.H.C., 2011. Sugarcane bagasse whiskers: extraction and characterizations. Ind. Crops Prod. 33, 63-66.

Teixeira, E.M., Oliveira, C.R., Mattoso, L.H.C., Corrêa, A.C., Paladin, P.D., 2010. Nanofibras de algodêo obtidas sob diferentes condiãçes de hidrõlise ócida. Polámeros 20, 264-268.

Wang, B., Sain, M., 2007. Isolation of nanofibers from soybean source and their reinforcing capability on synthetic polymers. Compos. Sci. Technol. 67, 2521-2527.

Yao, F., Wu, Q. Lei, Y. Weihong, G. Xu, 2008. Thermal decomposition kinetics of natural fibers: activation energy with dynamic thermogravimetric analysis Polym. Degrad. Stab. 93, 90-98. 